Communications in Physics, Vol.20, No.1 (2010), pp. 77-81

\title{
PHOTOCONDUCTIVE UV DETECTORS BASED ON ZnO FILMS PREPARED BY R.F. MAGNETRON SPUTTERING METHOD
}

\author{
NGUYEN VIET TUYEN, TA DINH CANH, AND NGUYEN NGOC LONG \\ Department of Physics, \\ Hanoi University of Science, Vietnam National University, Hanoi
}

\begin{abstract}
Highly c-axis oriented zinc oxide ( $\mathrm{ZnO})$ thin films were deposited on glass substrates by radio frequency (r.f.) sputtering. The photoconductor UV detector based on ZnO films, having a metal-semiconductor-metal (MSM) structure with interdigitation configuration, were fabricated by using aluminium $(\mathrm{Al})$ as a contact metal. The characteristics of dark and photocurrent of the ultraviolet $(U V)$ detector and the UV photo-response of the detector were investigated. The linear current-voltage ( $I$-V) characteristics under both forward and reverse bias exhibit ohmic metalsemiconductor contacts. Under illumination by monochromatic light at a wavelength of $365 \mathrm{~nm}$, the photo-generated current was measured to be $0.56 \mu \mathrm{A}$ at a bias of $6 \mathrm{~V}$. The photo-response decay in these devices is slow.
\end{abstract}

\section{INTRODUCTION}

$\mathrm{ZnO}$ is a wide and direct band gap $(3.3 \mathrm{eV})$ semiconductor material with hexagonal wurtzite structure and has potential applications for surface acoustic wave devices (SAW), gas sensors, transparent conducting layers, light emitting diodes (LEDs), ultraviolet (UV) lasers and especially the UV detector $[1,2]$. The reports of ZnO UV detector mainly focus on metal/semiconductor/metal (MSM) structure which contains ohmic contact based photoconductive type $[3,5]$ and schottky-barrier-based photovoltage type $[4,6$, 7]. The photoconductive detector is easy to achieve higher gain and photoresponsitivity, but the photoresponse time is usually longer than other types because of the persistent photoconductivity.

In this paper, we describe the photoconductivity in the $\mathrm{UV}$ region of $\mathrm{ZnO}$ thin films grown by a sputtering method and show that the $\mathrm{ZnO}$ thin films are advantageous and promising materials for use in ultraviolet sensor.

\section{EXPERIMENT}

$\mathrm{ZnO}$ thin films were prepared by a radio frequency (r.f.) sputtering technique which has a base pressure of $5.8 \times 10^{-3}$ Torr. Glass substrates with the size of $20 \times 20 \mathrm{~cm}^{2}$ were placed on the sample holder which is parallel to the $75 \mathrm{~mm}$-diameter $\mathrm{ZnO}$ target. Before sputtering, the glass substrates were ultra-sonically cleaned sequentially in distilled water, acetone, alcohol, and distilled water. After 5 minutes of sputtering in argon (Ar) plasma, with r.f. power of $200 \mathrm{~W}$ at deposition temperature of $150^{\circ} \mathrm{C}$, a $\mathrm{ZnO}$ film was deposited on the glass (the thickness of the $\mathrm{ZnO}$ thin film is about $0.6 \mu \mathrm{m}$ ). Aluminium was used as 
a contact metal because of its electron negativity. A $200 \mathrm{~nm}$ thick Al film electrode with interdigitation (IDT) configuration was patterned on the sputtered $\mathrm{ZnO}$ surface with a shadow mark by thermal evaporation at $250^{\circ} \mathrm{C}$.

The crystal structure and growth direction were investigated by using a X-ray diffractometer (D5005, Bruker, Germany), and the surface morphology was studied by using a scanning electron microscope (JSM 5410 LV, Jeol, Japan) and an atomic force microscope (AFM). The optical properties in the visible region were studied by employing an UV/VIS spectroscope (UV 2450 PC, Shimadzu, Japan) and the photoluminescence (PL) spectra were measured at room temperature by a spectrofluorometer (FL 3-22, Jobin Yvon Spex, USA).

\section{RESULTS AND DISCUSSION}

The $\mathrm{ZnO}$ film, prepared with a $\mathrm{ZnO}$ target, exhibited columnar grain growth with a strong c- axis orientation perpendicular to the substrate surface. Fig. 1 shows a typical $\mathrm{X}$-ray diffraction pattern for the $\mathrm{ZnO}$ films.

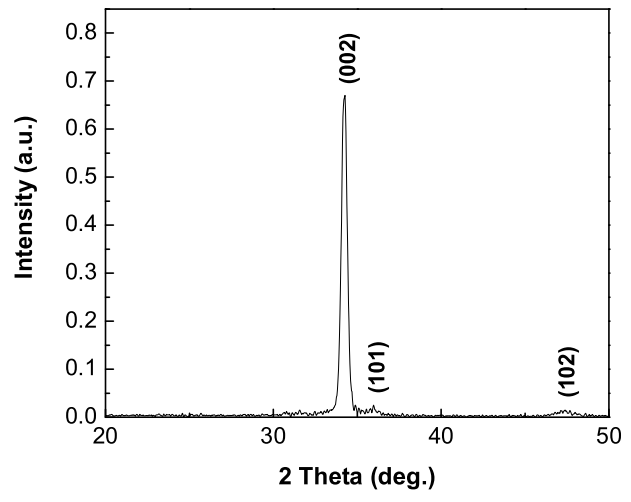

Fig. 1. XRD pattern of $\mathrm{ZnO}$ film deposited on glass substrate

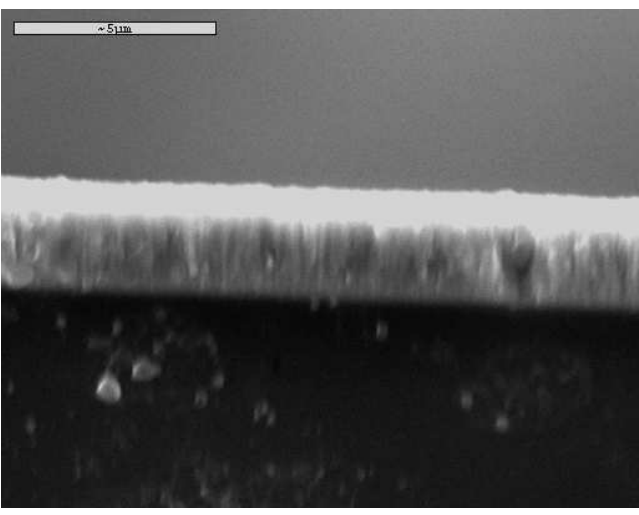

Fig. 2. SEM photograph of $\mathrm{ZnO}$ thin films on glass substrate

A strong diffraction line appears at $34.4^{\circ}$, which is assigned to (002) diffraction peak of hexagonal $\mathrm{ZnO}$. The lattice constants were calculated to be $a=0.3249 \mathrm{~nm}$ and $c=0.5212 \mathrm{~nm}$ utilizing the observed (002) diffraction peak, which is slightly larger than a reported value of $a=0.3248 \mathrm{~nm}$ and $c=0.5206 \mathrm{~nm}$ for bulk $\mathrm{ZnO}$ crystal [8]. Consequently, it is obvious that the hexagonal $\mathrm{ZnO}$ films obtained in this work are of high crystalline quality. A typical SEM photograph of an obtained $\mathrm{ZnO}$ film is shown in Fig. 2. A thickness of the film was typically $0.6 \mu \mathrm{m}$.

A representative AFM image of the high-quality $\mathrm{ZnO}$ film is shown in Fig. 3. The mean square roughness for $1.5 \times 1.5 \mu \mathrm{m}^{2}$ of the $\mathrm{ZnO}$ film is less than $4 \mathrm{~nm}$, suggesting that the surface is flat and smooth. These results indicate that the sputtered $\mathrm{ZnO}$ thin films are appropriate for fabrication of UV detectors. 


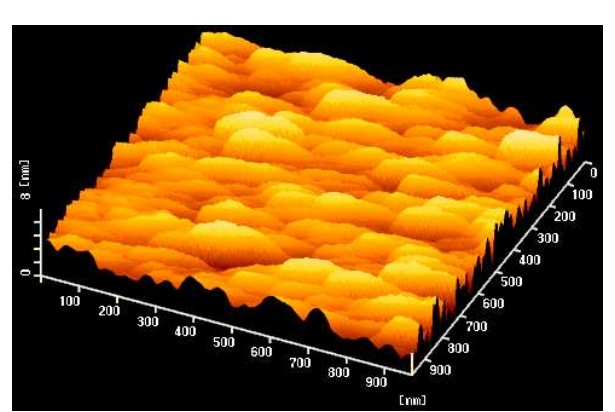

Fig. 3. AFM image of $\mathrm{ZnO}$ film

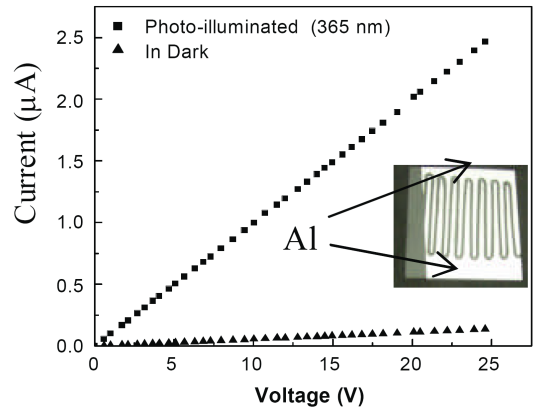

Fig. 4. Dark and photo-illuminated of $\mathrm{Al} / \mathrm{ZnO} / \mathrm{Al}$ photoconductive detector (the inset shows the IDT electrodes of $\mathrm{ZnO} \mathrm{UV}$ detector)

The $\mathrm{Al} / \mathrm{ZnO} / \mathrm{Al}$ (MSM) structure with interdigitation (IDT) configuration was used to evaluate the UV detector performance. The inset in Fig. 4 is the partial IDT electrodes of $\mathrm{ZnO}-\mathrm{UV}$ detector. The measured dark and photo-illuminated I-V characteristics are shown in Fig. 4. The linear I-V relation under both forward and reverse bias exhibits ohmic metal-semiconductor contacts. The detector operates in the photoconductive mode. The dark current for bias voltage of $6 \mathrm{~V}$ was $0.003 \mu \mathrm{A}$. The low dark current is helpful to enhance the detector's signal to noise $(\mathrm{S} / \mathrm{N})$ ratio. Under illumination by monochromatic light with a wavelength of $365 \mathrm{~nm}$, the photocurrent obtains a value of $0.56 \mu \mathrm{A}$ at a bias of $6 \mathrm{~V}$.

The measured results of spectral response of the photocurrent measurements of $\mathrm{Al} / \mathrm{ZnO} / \mathrm{Al}$ structure are shown in Fig. 5. The photocurrent maximum is at around $365 \mathrm{~nm}$ $(3.40 \mathrm{eV})$ and at the longer wavelengths it drops roughly by $50 \%$. This is because when a light with photon energy greater than the band-gap value is absorbed by the semiconductor, the photo-generated carriers are excited through the metal-semiconductor-metal junction giving rise to a change in the electrical conductivity. At the longer wavelength side of the photocurrent maximum a cut-off is observed. This cut-off corresponds to the bandgap of $\mathrm{ZnO}$. Although the cut-off is not sharp, more than two times drop in photocurrent value was observed from 365 to $405 \mathrm{~nm}$. This indicates that sensitivity of sputtered $\mathrm{ZnO}$ film in the UV region is high enough for using it as UV detector material.

The photoresponse decay for the device under $6 \mathrm{~V}$ bias at room temperature has been measured. Before each experiment, the samples were kept in dark for at last $12 \mathrm{~h}$, and then excitation light was turned on for $2 \mathrm{~h}$. Fig. 6 shows a typical slow photoresponse decay. It takes $30 \mathrm{~s}$ for the signal to drop to $50 \%$ of its maximum value. This might be due to the presence of defect states within the band gap of the polycrystalline ZnO films. The photo-generated carriers can be trapped repeatedly by these defect states, therefore, that can lengthen the photoresponse decay.

Fig. 7 shows the transmission spectrum of $\mathrm{ZnO}$ thin film. There is a steep absorption edge at $375 \mathrm{~nm}$. The transmission coefficient is more than $90 \%$ at the visible light region and is zero at the UV light region. This indicates that the thickness of $0.6 \mu \mathrm{m}$ for $\mathrm{ZnO}$ film is enough for the UV light absorption for formatting the photocurrent. 


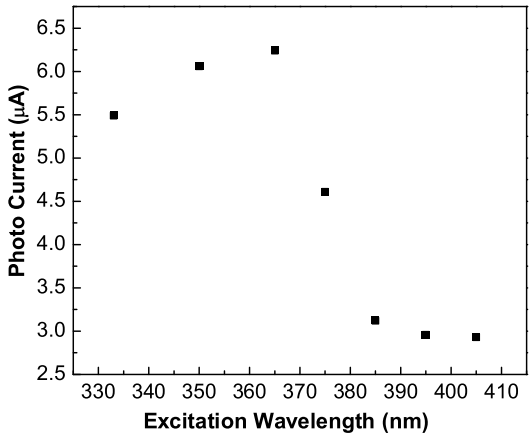

Fig. 5. Photocurrent spectrum of Fig. 6. Photoresponse decay of $\mathrm{ZnO}$ photoconduc$\mathrm{Al} / \mathrm{ZnO} / \mathrm{Al}$ photoconductive detector

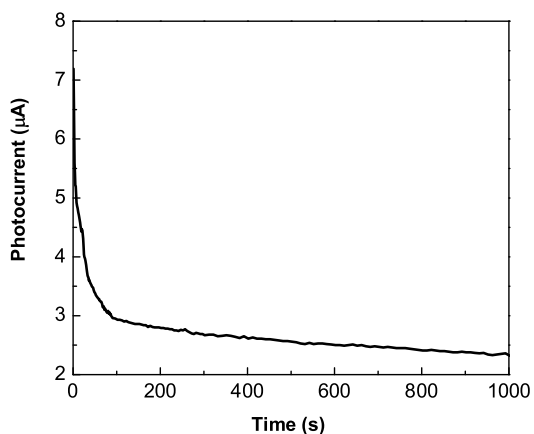

tive device

In order to elucidate the behavior of photo-generated carriers at different excitation wavelength, we have examined the absorption and photoluminescence spectra of $\mathrm{ZnO}$ film at room temperature (Fig. 8). An exciton peak is observed at approximately $367 \mathrm{~nm}(3.38$ $\mathrm{eV}$ ) in the absorption spectrum. In the PL spectrum, two emission bands are observed, one is at $379 \mathrm{~nm}(3.27 \mathrm{eV})$ near the band edge and a broad one is at $535 \mathrm{~nm}(2.32 \mathrm{eV})$.

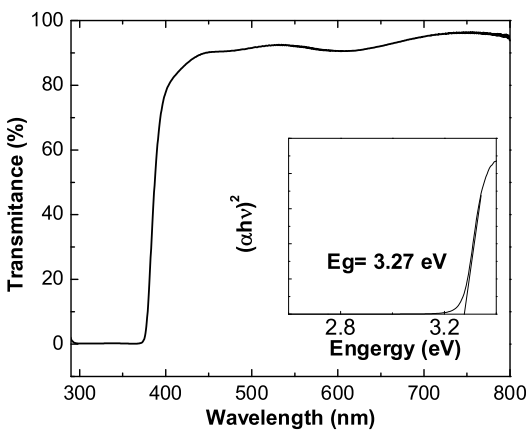

Fig. 7. Transmission spectrum of $\mathrm{ZnO}$ thin film

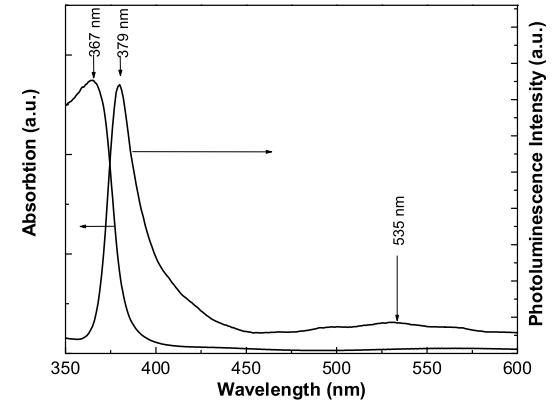

Fig. 8. Absorption and PL spectra of $\mathrm{ZnO}$ thin film at room temperature

The near band edge emission is due to free exciton recombination, although it exhibits slightly red shift from the absorption peak. The broad PL band is usually related to the defects formatting deep-levels in the band gap, which are frequently observed in $\mathrm{ZnO}$ thin films. It can be noticed that the wavelength of $365 \mathrm{~nm}$ at which the photocurrent obtains maximum value is approximate to the wavelength of $367 \mathrm{~nm}$ at which the absorbance is strongest. This indicates that photocarriers are generated by the absorption process near the band edge. 


\section{CONCLUSION}

Highly c-axis oriented $\mathrm{ZnO}$ films were deposited on glass substrates by r.f. magnetron sputtering technique. The MSM photoconductive UV detectors based on $\mathrm{ZnO}$ thin films were fabricated by using $\mathrm{Al}$ as contact metal. The $\mathrm{I}-\mathrm{V}$ characteristic of the detector is linear under dark or $365 \mathrm{~nm}$ UV light illumination. Under illumination by monochromatic light with a wavelength of $365 \mathrm{~nm}$, the photocurrent was $0.56 \mu \mathrm{A}$ at a bias of $6 \mathrm{~V}$. Photoresponse decay for such film is very slow. The results of the photoresponce, absorption and photoluminescence measurements of the $\mathrm{ZnO}$ films allow to affirm that photocarriers are generated by the absorption process near the band edge.

\section{ACKNOWLEDGMENT}

The authors wish to thank the Vietnam National University (Project No QT 08-16) for financial support.

\section{REFERENCES}

[1] Z. Q. Xu, H. Deng, J. Xie,Y. Li, X. T. Zu, App. Surface Science, 253 (2006) 476.

[2] Q.A. Xu, J.W. Zhang, K.R. Ju, X.D.Yang, X. Hou, J. Crystal Growth, 289 (2006) 44.

[3] S. Mridha and D. Basak, J. App. Phys., 101083102 (2007) 1.

[4] Z. Q. Xu, H. Deng, J. Xie, Y. Li, Y. Li, X. T. Zu and S. Xue, J. of Sol-gel Scie. and Tech., 36 (2005) 223.

[5] Jichen and T. Fujita, Jpn. J. App. Phys., 41 (2002) 203.

[6] D. Balsak, G. Amin, B. Mallik, G.K. Paul, S.K. Sen, J. Crystal Growth., 256 (2003) 73.

[7] K. Omichi, K. Kaiya, N. Takahashi, T. Nakamura, S. Okamoto and H. Yamamoto, J. Mater. Chem., 11 (2001) 262.

[8] F. Masuoka, K. Ooba, H. Sasaki, H. Endo, S. Chiba, K. Maeda, H. Yoneyama,I. Niikura, and Y. Kashiwaba, Phys. Stat. Sol., 4 (c) 3 (2006) 1238.

Received 05 May 2009. 